\title{
Facilitation of conduction in left bundle of His
}

\author{
A. Mazzoleni and E. Fletcher \\ From the Veterans Administration Hospital and the University of Kentucky \\ Medical Center, Lexington, Kentucky, U.S.A.
}

A patient with a combination of Mobitz I AV block (Wenckebach phenomenon) and intermittent left bundle-branch block is presented. Group beating is present with left bundle-branch block in the first beat of each sequence and normal intraventricular conduction in the following beats.

Supernormal conduction in the left bundle induced by the first beat explains the paradoxical improvement of intraventricular conduction as atrioventricular conduction becomes progressively more impaired.

$A$ less obvious phase 4 depolarization following the shorter $R R$.intervals may account for this state of supernormality.

When conduction in the His Purkinje system is impaired, the site of delayed conduction, either anterograde or retrograde, may be influenced by a preceding impulse in such a way that conduction is enhanced, i.e. it is made more efficient (Pick, Langendorf, and Katz, 1962). Supernormal conduction in the atrioventricular conduction tissues may occur in partial atrioventricular block. Likewise, the retrograde impulses in complete orthograde atrioventricular block may reach the atria, being facilitated through the area of block by the influence of the preceding sinus impulse (Scherf and Schott, 1953; Fletcher and Morton, 1968). In most cases of 'normalization' of conduction by such physiological mechanisms, the site of impaired conduction has been located above the bifurcation of the main bundle of His. In the case described below, the site of the block was in the left bundle of His. Intraventricular conduction was made more efficient in an unexpected manner and an explanation of the mechanism involved is given, based on the established physiological principles.

\section{Case report}

The Fig. represents a disturbance of rhythm recorded over a few days from a man of 45 years during a terminal myocardial infarction. The ventricular rhythm is irregular, the ventricular responses are arranged in groups of 4 to 5 beats. Each group starts with a sinus beat with a PR interval measuring $0.2 \mathrm{sec}$ and a QRS interval measuring 0.12 to $0.16 \mathrm{sec}$ due to complete left bundle-branch block. The QRS complexes in the beats after the first beat have an unexpectedly shorter duration: $0.09 \mathrm{sec}$. Each group of beats is terminated by a blocked sinus $\mathbf{P}$ wave. Sinus $\mathbf{P}$ waves precede the second and successive beats of each group and the PR intervals are prolonged

FIG. Wenckebach atrioventricular block with group beating. Supernormal conduction in the left bundle of His following the first beat of each group.
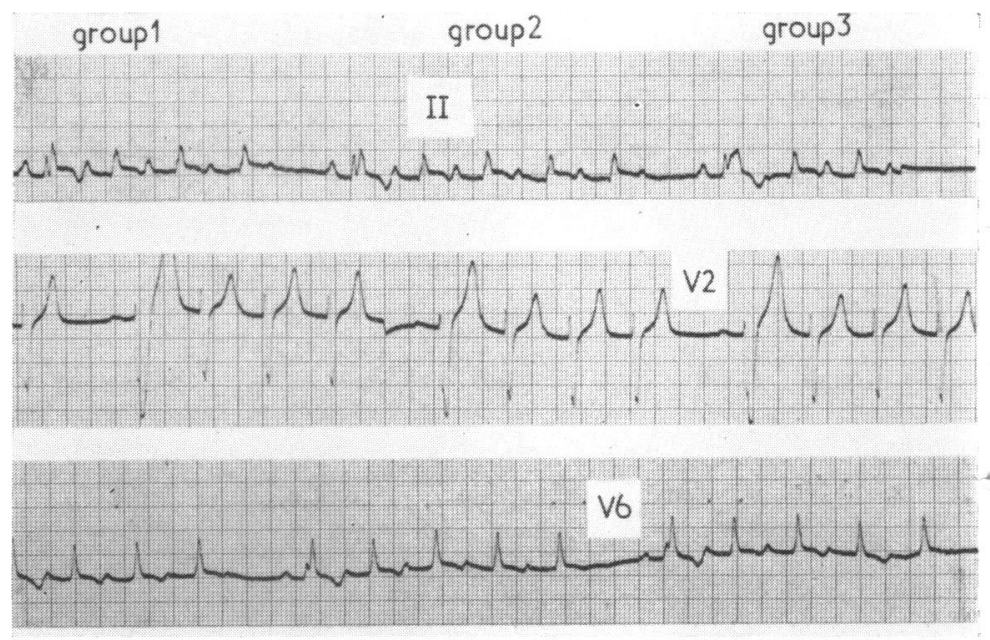
from 0.23 to $0.27 \mathrm{sec}$ (Fig. I, lead II, group 2). At the same time the QRS duration is shortened from 0.12 to $0.09 \mathrm{sec}$.

Wenckebach block therefore in the conduction system above the bifurcation of the main bundle of $\mathrm{His}$ is associated with improved conduction in the left bundle of His. The $P$ waves after the first beat are closely related to the $T$ wave and would not usually be expected to be associated with improved intraventricular conduction time. It appears, therefore, that some change occurs at the site of the block in the left bundle of His to alter its refractoriness at a critical time to enable delayed supraventricular impulses to be conducted more efficiently. The supernormal phase of recovery affords an explanation corresponding to Type A for atrioventricular conduction of Pick et al. (1962). The second to the fifth impulse reached the site of left bundle-branch block at its period of supernormality operating within the boundaries of its phase of refractoriness, and thereby facilitated conduction. Lastly, it might be mentioned that an increased 'phase 4 depolarization' may explain the intraventricular block of the first beat of each group following long cycle length, but irrespective of such possibility the normalization of intraventricular conduction must depend upon changes at the site of the block induced by the first beat.

\section{Discussion}

Supernormal conduction has been reported in atrioventricular junctional tissues by Pick et al. (1962) and in a few instances in the bundle-branches (Contro, Magri, and Natali, 1956; Mihalick and Fisch, 1970). In the case illustrated in this paper, progressive impair- ment of atrioventricular conduction is associated with improvement in intraventricular conduction. The two phenomena may be interdependent due to critical timing of arrival of sinus impulses at the site of the block at the time when conduction was enhanced by the supernormal phase of recovery. Two distinct areas of block were present in the conducting tissues in the atrioventricular node and in the left bundle of His. Supernormal conduction in the latter explains the paradoxical improvement of intraventricular conduction with Wenckebach atrioventricular block.

\section{References}

Contro, S., Magri, G., and Natali, G. (1956). Premature beats overcoming impaired intraventricular conduction. Supernormal phase of intraventricular conduction. American Heart fournal, 51, 378.

Fletcher, E., and Morton, P. (1968). Atrioventricular dissociation with intact retrograde conduction. British Heart fournal, 30, 458.

Mihalick, M. J., and Fisch, C. (1970). Supernormal conduction of the right bundle branch. Chest, 57, 395.

Pick, A., Langendorf, R., and Katz, L. N. (1962). The supernormal phase of atrioventricular conduction. I. Fundamental mechanisms. Circulation, 26, 388.

Scherf, D., and Schott, A. (1953). Extrasystoles and Allied Arrhythmias. Heinemann, London.

Requests for reprints to Dr. A. Mazzoleni, Veterans Administration Hospital, Lexington, Kentucky 40507, U.S.A. 